small quantity of ether to the first stage of etherization; it did not reach the disturbing period at all. She felt no pain, and the operation was done without any trouble whatever. It could not have been done so quickly and efficiently with either of the aniesthetics alone, or by the single use of cocaine.

I would like to ask Dr. Colburn if there are any distinguishing features to differentiate these two forms that he would lay special stress on"

Dr. Colburn: I endeavored to point out the two forms of the disease in the differential diagnosis. In the simple vesicle or pemphigus we have no inflammatory symptoms, excepting those incident to the irritation of the lid in moving over the vesicle. In keratitis bullosa we have the inflammatory symptoms preceding and following the formation of the vesicle. And then, furthermore, in keratitis bullosa the vesicle occurs almost invariably in eyes that have been previously diseased, and in those in which there has been marked interference with the nutrition. In the case which I first mentioned, it would be almost problematical whether the condition was related to keratitis bullosa or pemphigus cornea were it not that it had persisted for so long a time; from the fact that there had been a constant irritation for a period preceding the formation of the vesicle, during its development, and after it had emptied, it would point to its being what we know as a keratitis bullosa. Then there is the period of anrsthesia that occurs for a short time after the vesicle is thoroughly filled, and very frequently in these cases, so far as I can find from the literature of the subject, there is increased tension of the eye. In pemphigus cornea I have not seen a single case of recurrence of the disease. Another point of difference is that in simple vesicle you can by pressure through the lid extend the vesicle in any direction. In keratitis bullosa you cannot so extend it; it is perfectly rigid. The vesicle will rupture after firm pressure, but will not extend beyond its primary limits. In this case, I think that the constant attempts to remove the vesicle increased the irritable condition of the eye and tended to produce sympathetic irritation in the other eye. Whether there was any sympathetic inflammation excited, I do not know. That could only be told by following the case for some time.

Dr. Patton: You would lay stress on the history or absence of continued irritation in the eye, would you not?

Dr. Colburn: Yes. If I were convinced that the patient had a recurrent vesicle, and that this was but one of many, I should call it keratitis bullosa if the case had the other symptoms of inflammatory invasion.

Dr. Geo. H. Cleveland: I would like to ask Dr. Colburn what connection there is between these troubles and a simple ulcer of the cornea? Or whether a simple ulcer of the cornea may result from these affections? In a simple inflammation, involving corneal layers with destruction of the layers, would perforation oceur if the case continued? Furthermore, what is the exact pathology of this trouble(keratitis bullosa)? Have microscopical examinations been made in reference to a specific organism? If so, what effect would the stronger antiseptics have in the treatment of both affections?

Dr. Colburn: To the query, whether they would produce ulcer of the cornea, I would say this, that, I presume, if any of those vesicles were ruptured in an eye that contained any of the pus-producing microörganisms, you might get an ulcer following; but there must necessa rily be some infection, and the first form is pretty well guarded from infection, because it is evident from the investigations of Arlt that it has an epithelial lining membrane, and that would rather protect it from inoculation. In the case of pemphigus cornea, where there are simply vesicles to break down, I presume that, if under proper conditions they were infected, an ulcer would be produced. I do not see why they should not be subject to infection as well as when a foreign body punctures the epithelial layer. The tears are so well provided with the power of destroying, washing out and keeping clean the conjunctiral sac, that it seldom is infected. If the nasal duct and lachrymal sac are inhabited by organisms, I have no doubt they might extend and produce trouble.

Regarding the true pathology, I think very little definite of the first form is known. The examinations made by Arlt would seem to indicate that there is a new formation between the epithelial layer and Bowman's membrane, and that it is speedily reproduced. It will take four or five days for the new epithelium to extend over the denuded area, yet bulke will appear within eight days from the time one has been destroyed. I do not think there is any microörganism entering into the cause of its formation.

I)r. J.J. 1[. Angear: Charcot has taught us that certain ulcers follow disease of the spinal cord. Pathologists agree, I think, that herpes is the result of nerve irritation; that we have ulcers of the eye from the destruction of the optical branch of the fifth pair of nerves. I have listened to the paper attentively, and I thought if there was anything pertaining to the nervous system that was the real cause of these ulcers; or whether pathologists have thrown out the least intimation with reference to this affection being a nerve trouble.

Dr. Colburn: I purposely avoided the discussion of herpes, as it comes under an entirely different head. So far as I have been able to learn there is no relation between the nerve irritation and the formation of these vesicles; there may be indirectly in the simple resicle. There you have a separation from the impinging of some foreign body on the cornea-a separation of the epithelial layer from its basement membrane, which may be due to paralysis of the terminal nerve supply. It is purely local, however, and it is simply the terminals that are so affected. Enucleation should be a last resort or in cases where the constant irritation is exhausting the patient or threatening the fellow eye with sympathetic disease.

Arlt (Ware) p. 134, 188.

Landesberg, Archives of Ophthalmology, p. 135, 1877.

Brugger, Monatsblatter Augenheil, xxiv Jahrgang, s. 500, 1886.

Hansen, Grut \& Horner. Noyes.

Berry, Diseases of

Critchett, Jules. Trans. Ophthal. Societr, Vol. 5, p. 46, 1884

\section{FOUR CASES OF ORBITAL TRAUMATISM}

RESULTING IN IMMEDIATE MONOCULAR BLINDNESE THROUGH FRACTURE INTO FORAMEN OPTICUM. IN

ONE OF THESE CASES THE BLOW WAS OVER

THE LEFT ORBIT CACSING BLINDING OF

THE RIGHT EYE.

BY PETER A. CALLAN, M.D.

SUTGEON NEW YORK EYE AND EAR INFIRMARY, PROF. OF OPIITHALMOLOGY, POST-GRADE:ATE MEDICAL COLLEGAE, N, Y.

The ancients as far back as Hippocrates, were aware that blows on eyebrows or skull were followed at times by immediate monocular blindness.

Hippocrates wrote that amaurosis sometimes follows wounds inflicted on eyebrows or other parts of head.

During the past hundred years medical writers alluded to the possibility of sudden blindness following injuries of the skull. The etiology was in doubt; Beer's theory being most in vogue, viz.: that the injury to the supra orbital nerve caused the blindness; to this, later writers added the infra orbital nerve as a probable cause. Lawrence ${ }^{1}$ gives in his book four cases in detail, and remarks that althongh the fact appeared to be well established, no one furnished the history of any cases, referring especially to Beer and Wardrop, both of whom had written on this subject. Since Lawrence's time there has been no lack of recorded cases, but it remained for R. Berlin to establish on a sound basis the true pathology. At the twelfth meeting of the German Ophthalmologists in Heidelburg in 1879, Berlin, besides reporting three of his own cases, gave an analysis of Von Holder's very carefully made autopsies in 126 cases of skull fracture. Von Holder for thirty-three years filled a position, corresponding to a medical coroner. In eighty-eight of the 126 cases the fracture involved the base of the skull, and in eighty the orbital roof was likewise fractured, making 90 per cent. In fifty-four cases, or 60 per cert., the lesion extended into the foramen opticum.

Unfortunately, these cases had no clinical data, 
but at the same time they established beyond doubt the frequency with which the optic canal was involved. In forty-two of the 126 cases, the injury was due to gunshot wound through mouth or temples, and in eleven, falling on the head, while only one, where the skull was rum over.

In the cases where death does not result from the injury, the patient is stunned or dizzy, may suffer from shock, bleeds from ear, mouth or nose, and soon discovers that one eye is blind. There may be cedema of the eyelids, eye is diverged and protruded, pupil enlarged and irresponsive to direct rays of light. Ophthalmoscopic examination immediately after injury is, as a rule, negative, but within two weeks, at the very utmost, pallor of the optic nerve is noticeable, and often much sooner; some regain enough vision to count fingers at some feet, the eye remains divergent, with enlarged pupil. Optic nerve atrophic.

The explanation of the fracture involving the foramen opticum is as follows-ais it appears to me:?

The frontal bone unites with the nasal, submaxillary, lachrymal, and ethnoid bones by a continuous line of sutures, until the lesser wing of the sphenoid is reached, and at this point, the suture line bifurcates forming an obtuse angle, and quite near the apex of the angle is the foramen opticum. The jar made by the blow would find its weak point along this line of sutures, and the first resistance would be at the bifurcation adjacent to the foramen opticum. The movement or jar could not follow both lines with equal force at and beyond the bifurcation, consequently the unequal strain would result in fracture of the bone into the foramen opticum, causing compression of the optic nerve and sudden loss of vision in the eye.

G. F. S., age 23, artist, was brought to me March 3,1890 , while suffering from shock. From his companions I learned that while fencing with a friend, a thrust of the friend's foil had broken through $\mathrm{Mr}$. S.'s mask, and the buttoned point entered the right orbit between the nose and the eyeball. I saw him forty minutes after the accident, and then the right globe was somewhat protruded down and outward. Chemosis and eschymosis of lower ocular conjunction with a slight irregular tear over the body of the right internal rectus muscle. Eyeball immobile, pupil dilated almost ad. maximum, and not responsive to direct rays of light, but acted consensually with the fellow eye. Total loss of light perception of that eye. Ophthalmoscope showed a slight haze of fundus, but not enough to prevent a good view of optic nerve and media. At the end of the first week after the injury the protrusion and displacement of the globe had disappeared, the eye diverged and patient could control all the ocular muscles except the rectus internum, chemosis still remaining. Ophthalmoscope showed arteries and veins normal in size, with no haziness of media. On the tenth day for the first time patient had light perception on nasal side, pupil moderately dilated and somewhat responsive to direct rays of light. At the end of the third week there was well marked begining atrophy of the optic nerve.

The patient has been under my observation ever since the accident; well marked atrophy ensued, but he still retains a small sector of the nasal field, where there is slight perception. Pupil larger than in the fellow eye, and responds fully to direct rays of light. Slight amount of divergence of eyeball, but the parts much worse. The oedema had increased patient can
canthus.

Ludwig M., aged 24. Was admitted to my service the New York Eye and Ear Infirmary, April 1, 1891. He complained about the blindness of his right eye, giving the following history: At 1 A.M. of the day of admission to the infirmary he was waylaid by a rival and struck over the left eye; with regard to what he was hit with, he does not know, but thinks it was only the fist. For a moment he was stunned and dizzy, but did not fall nor become unconscious, and was led home by the young woman who was the cause of the assault. From the moment of the blow over the left eye he is positive that the right eye became blind. He bled from the nose and vomited blood, which must have been previously swallowed, and suffered from shock. When I saw him fifteen hours after the injury, there was slight abrasion of the skin of upper left eyelid, extending toward the nose, with some cdema of both upper and lower eyelids; movement of the left eye normal; oph thalmoscopic examination showed hyperopic astigmatism (O.D. +1.00 cyl. $\left.90 \frac{2}{2} 0\right)$.

Right eye totally blind. Movements of the globe normal, no divergence nor protrusion; some conjunctival injection; pupil widely dilated and only responded consensually to light. Ophthalmoscopic examination gave normal fundus. Seventy-two hours after injury ptosis marked, and in ninety-six hours ophthalmoplegic. One week after his admission to the infirmary the optic nerve of the right eye began to grow pale and in three weeks the atrophy was marked. April 15, 1891, two weeks after the injury to his left eye, the right eye began to have some light perception in the upper nasal field, and he could now move eyeball to a very limited extent. Ptosis not so marked. May 11, 1891, six weeks after injury, the movement of eyelid and globe had greatly improved, but there was still slight divergence, pupil not so dilated. Can form a fair estimate of large objects when held about eighteen inches, in the upper nasal field. The atrophy of the optic nerve has increased with the disappearance of the capillaries and total pallor of disc. Since then patient has been lost sight of, and all my efforts to find him have been, so far, unsuccessful.

M. H., 34. I saw patient Oct. 3, 1891, for the first time, when I elicited the following history. He was struck on morning of Sept. 20, 1891, over the left orbital ridge with a lighted lamp, thrown at him by a boon companion. As well as he could estimate, the lamp was thrown a distance of ten feet; the blow dazed him, and he staggered back against a wall of the room, which prevented his, falling. He felt slightly dizzy, but had no nausea or other symptoms of shock. In less than one half hovir he was asleep. He awakened at 8 A.M. the same day, having slept soundly for six hours, and discovered that his left eye was blind. Patient immediately consulted Dr. Henry Moffat, of Yonkers, N. Y., who found an irregular wound of $1 \frac{1}{2}$ inches long extending up and backward from under edge of left eyebrow, likewise a slight abrasion of skin on inner half of upper eyelid. Marked cedema of botl upper and lower eyelids, but not much displacement of eyeball, pupil moderately dilated, with total loss of light perception of left eye.

Dr. Moffat saw patient again on the fourth day after injury, when he found the general appearance of 
and the lower eyelid was everted and very much swollen, with chemosis of eyeball. The eveball was slightly displaced down and outward. I saw the patient on the 2nd of October (he liaving been referred to me by Dr. Moffat) ; œdema of lids had disappeared, eye slightly deranged, with some redness of conjunctiva, pupil moderately dilated which did not respond to direct rays of light, but acted consensually with the fellow eyc. Ophthalmoscopic examination showed some pallor of optic nerve of left-but fundus otherwise normal. Vision nil. Right normal in every respect.

Dec. 5th, 1891. Patient presented himself, after an absence of three weeks, when I found the divergence not so marked as on the previous visit, pupil moderately dilated, but there was enough vision regained for the patient to count my fingers at eight feet. Ophthalmoscopic exainination showed more marked pallor of optic; nerve fundus otherwise normal. Dec. 27, 1891, condition remains the same. Jan. 17, 1892. Still able to count my fingers when held about eight feet from his left eye, but the ophthalmoscope showed the atrophy of optic nerve more marked.

Julius S., aged 30. Patient fell from the track of the Metropolitan Elovated Railroad, on the afternoon of the 9 th of October, 1891. He was conveyed to St. Vincent's Hospital, when on examination by the House Surgeon, Dr. Shea, there was found blood coming from right ear and nose, left side of head and face contused, with wound of left orbital ridge and patient. in a semi-unconscious condition. On the third day after the fall of patient from the track I saw him; he lay in a stupor and when aroused he complained of great pain all over his head. In falling he tried to save his face, so that he struck on the left side of his head. He complained about his left eye, saying that since the accident it had become blind. There was no swelling of the eyelids, the eyeball was slightly diverged, but he could move the cornea well in toward the inner canthus. no protrusion of the globe, pupil slightly enlarged, but it did not respond to direct rays of light, but acted feebly consensually with that of right eye. Ophthalmoscopic examination showed the fundus of left eye normal. No light perception. Right eye normal in all respects, except the pupil was rather contracted. Saw patient at regular interrals and at the end of two weeks there was found by the ophthalmoscopic examination, decided pallor of of optic nerve (left eye). Patient continues under my observation, and now, Feh. 1892, optic nerve atrophy pronounced of left eye. No light perception.

The medico-legal aspect of this lesion is quite apparent and is of considerable importance.

I am fully satisfied that the optic foramina are frequently involved in fractures of the skull, but as most of the severe cases die, this lesion is neither looked for nor recognized. If the autopsy is not carefully made, hy removing all the dura mater within the cranial cavity, and this means bard work, a fissure involving the optic foramen easily escapes attention. It has been my lot to see the four cases which comprise this paper within the past two years, which is remarkable from the fact that there are not more than 80 recorded cases in medical literature.

A twenty-five per cent. ointment of resorcin in vaseline is recommended in the treatment of rodent ulcer.

\section{A CASE OF MALIGNANT PLSTULE.}

Reported to the Bunscombe Co. Medical society, Feb. 1, 189. BY KARI, VON RUCK, B.S., M.D., OF ASHEVILLE, Y. C:

That comparatively rare affections may come to our notice when least expected we all have learned from experience, and it is certainly one of the last of improbable cases that I should have imagined to present itself to me, the more so, as I am not engaged in general practice.

Nevertheless, on Dec. 8th, a patient who has been under my care more or less for the last three years, on account of his pulmonary affection, called upon me with the following statement: on noon of the day before, he noticed a spot on the inner aspect of the first phalanx of the fore-finger of his left hand, looking like a flea bite, which attracted his attention on account of severe itching; by evening a vesicle had formed surrounded by a red areola, and a burning, stinging sensation was also present; the finger and surrounding parts had become slightly swollen.

The patient presented himself the following morning, calling my attention to his finger. The vesicle was now about three-eighths of an inch in diameter, the elevated epidermis was of a dark discoloration and gangrenous, the base was indurated, and spontaneous rupture of the vesicle had occurred, a serous, pink-colored fluid discharging, so that a drop could be collected every five or ten minutes.

The first phalanx of the finger, the phalangometa-carpal joint, and the hand were distinctly swollen, the skin presenting a red blush, the vesicle had a stinging, burning sensation, the whole hand to the wrist pained him, the local temperature of the hand was distinctly increased to the touch; there were, however, nogeneral symptoms, unless a temperature of $99.5^{\circ} \mathrm{F}$., could be so interpreted.

The patient was in my office from 9:30 to 1 o'clock, and the swelling and size of the vesicle had undoubtedly increased; a very minute vesicle, independent of the larger one, which was not present in the morning, was now observed at the edge of the indurated base. Eight years ago, in the Hygienic Institute in Berlin, I saw experimental inoculations of guinea pigs and rabbits with anthrax bacilli, and within the last few months, I had reviewed the subject of anthrax in connection with some bacteriological studies-but for these circumstances, I should perhaps have had no suspicion of the serious character of the nature of this case.

From what I remembered, the probability of malignant pustule at once occurred to me, and my inquiries only served to strengthen the suspicions, while the local appearance and the history given by the patient conformed entirely to descriptions of my available, and promptly consulted medical literature. I suggested the propriety of consultation, which was readily concurred in by the patient, in the meanwhile subjecting the discharging serum to microscopical examination, with, however, negative results. While my consultant could not be more positive than I was myself, it was determined to endeavor to make a culture from the discharging serum, and to promptly and thoroughly destroy the vesicle and its base with fuming nitric acid. This was done accordingly, and the patient allowed to return home with instructions to return or send for us, should general symptoms, which were explained to him, occur. 